\title{
THE SEARCH AND RESCUE OPERATION IN COLLAPSED BUILDINGS CAUSED BY EARTHQUAKES--A CASE STUDY
}

\author{
Lih-Ren Sheu ${ }^{1}$, Ban-Jwu Shih², and Chuan-Wei Wu ${ }^{2}$ \\ ${ }^{1}$ Fire Department, Taipei City Government, Taipei, Taiwan, ROC \\ ${ }^{2}$ Associate Professor, Department of Civil Engineering, \\ National Taipei University of Technology, Taipei, Taiwan, ROC
}

\begin{abstract}
This paper uses the experience from the search and rescue operation at the DongXing Building, which collapsed in the Ji-Ji Earthquake, as a real example to study the risk factors that contributed to the deaths of the residents of the collapsed building. This paper also examines a possible strategic plan to rescue survivors from collapsed buildings, which combines various sources of information such as water mains, fire-fighting equipment, shelter locations, medical facilities, household registry information, lifelines, logistic supports, and the disaster management technology.
\end{abstract}

Keywords: search and rescue, building collapse rescue, Ji-Ji earthquake

\section{INTRODUCTION}

Up to October 13, 1999, the death toll of the Ji-Ji earthquake hit 2,333. A total of 10,002 persons were injured, 9,909 buildings completely collapsed, and 7,575 buildings partially collapsed. The economic loss was beyond estimation. Although located in the northern part of Taiwan, Taipei City still couldn't escape from this tremor, which nobody had experienced in the past one hundred years. The Dong-Xing Building located on the Bade road collapsed due to the strong shaking of the earthquake. In this disaster, 138 persons were injured, 73 persons died, and 14 persons were reported missing. This paper uses the search-and-rescue operation and the demolition of Dong-Xing Building as an example to examine the field rescue plans and the risk factors (such as building collapses, falling objects, gas leaks, and fires) that could contribute to human causalities. It is hoped that this experience can be used as future references for building collapse rescues, and more lives can be saved in major disasters.

\section{THE SEARCH \& RESCUE EFFORT OF THE COLLAPSED DONG-XING BUILDING}

\subsection{Site conditions}

The Dong-Xing Building was a 12-story multipurpose building with two levels of basement. The total floor area was $11,280 \mathrm{~m}^{2}$. Before the collapse, the first and second floors were occupied by The First
Commercial Bank, the $3^{\text {rd }}$ to the $10^{\text {th }}$ floor were apartments, the $11^{\text {th }} \& 12^{\text {th }}$ floor were the Sung-Shen Hotel, and the basements were used as parking garages. After the Ji-Ji earthquake, the building tilted toward the east side and collapsed with the northeast corner being the worst part of the building. The floor slab of the $8^{\text {th }}$ floor collapsed down to the ground. The weight of the building also squeezed the west side and the basement. The $6^{\text {th }}$ floor on the southeast corner also leveled to the ground, compressing the floors between the first and the $6^{\text {th }}$ floors. On the west side, floors above the $9^{\text {th }}$ floor (included) tilted severely (between 45 and 60 degrees), and floors below the $8^{\text {th }}$ floor (included) were brutally crushed. But, the first to the third floors on the southwest side were still intact. On the east side across the street from the Dong-Xing Building, the Hao-men-shihchia Building were hit and squeezed by the tilted Dong-Xing Building, causing severe damages on the columns, beams, and walls between the $2^{\text {nd }}$ and the $7^{\text {th }}$ floors. Finally, the $12^{\text {th }}$ floor of the Dong-Xing Building was sheared off and fell between the $3^{\text {rd }}$ and the $4^{\text {th }}$ floors of the Hao-men-shih-chia Building.

\subsection{The search and rescue process}

The Dong-Xing Building was distorted and crushed by the strong shaking of the earthquake. The fire department immediately dispatched 51 fire engines, 12 ambulances, and 309 fire fighters to the site of the collapsed building (Picture 1).

As mentioned, the Dong-Xing Building tilted toward the east side after the earthquake. The $1^{\text {st }}$ to the $8^{\text {th }}$ floors were crushed, and the building structures were distorted and deformed. Forty 
residents between the ninth and the twelfth floors were quickly rescued by the fire fighters, but there were another 100 persons still trapped inside the distorted and collapsed reinforced concrete structure building. At 2:30 A.M., smokes and burning smells started to appear. The fire fighters prepared fire hoses for possible flames and fires, and continued to rescue survivors through distorted windows and broken walls with electric scissors, electric saws, electric drills, and other equipment. Later on in the rescue operation, heavy smokes came out from every floor, and the entire building was soon surrounded by the clouds of the smokes. At around 4:50 A.M., a glaze engulfed the tenth and the eleventh floors, and quickly spread. The fire fighters started fighting the fire with water and continued to use cranes to rescue people trapped inside the building. The fire was extinguished at 6:55 A.M.

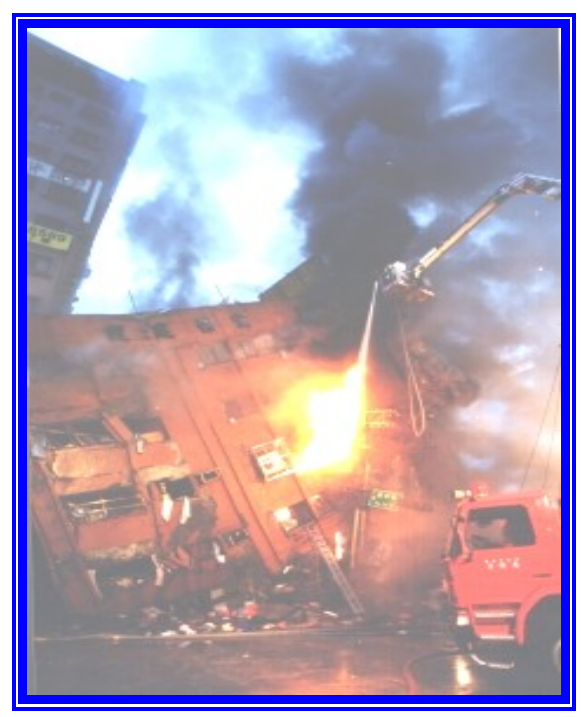

Picture 1. The collapsed Dong-Xing building.

At 1:00 P.M. on September 21, in order to reduce the pressure exerted on the lower portion of the building structure, the field commander ordered the excavators to start digging for the purpose of rescuing survivors, collecting evidences, and demolishing the building. They tore down the wall facing the Bade road to facilitate the rescue operations and reduce the pressure exerted onto the Hao-men-shih-chia Building. Up to 1:50 P.M. on the day of the disaster, 104 persons were rescued from the rubbles. In all, 109 persons were rescued on the first day. Four of them died in the hospital.

The next morning (September 22), in order to accelerate the rescue operation, it is decided to enlarge the digging area. Two excavators were used to tear down the building from the side facing the Bade road and the side facing a railroad. Whenever a space was cleared, rescue workers would enter the space immediately to search for survivors. Until the midnight of that day, rescue workers dug out six more bodies with no survivors. The death toll increased to nine.

On the third day after the disaster, it became apparent that it was too difficult to pull away piles of rubbles when the floors were crushed together like a thousand layer pie, which had slowed down the rescue operation. The fire fighters decided to be divided into seven groups with seven to ten persons in each group. Targeting the possible locations that residents could be trapped according to the floor plans and the information of the missing persons provided by their family members, the fire fighters used ladders, ropes, hand-held breakers, and search lights to search every void space. To be sure, each void space was searched three times by different teams on that day, but no survivor was found. Afterwards, in order to further speed up the search and rescue operation, it was decided to use large electric drills and heavy machinery to tear apart the building from top down. As the operation proceeded, more victims were found, and the death tolls hit 19 .

On the fourth day, after the critical 72 hours, the rescuers started full-scale excavations from the north and the south sides (facing the Bade road and the railroad). More heavy machinery such as excavators and bulldozers was used. Every excavator was assigned two fire fighters to monitor the excavation. Whenever a hidden space was uncovered, the fire fighters would enter the space to search for survivors. On the fifth day $(9 / 25)$, the excavation continued, but no more survivors were found. The total number of victims continued to rise and reached 36 persons. It was estimated that 40 to 50 persons were still missing.

On the sixth day, the rescuers had already demolished the building structure between the $8^{\text {th }}$ and the $10^{\text {th }}$ floors. The excavation continued with five excavators and five groups of rescue workers. At around 11:15 A.M., a miracle happened when the rescue workers found the Sun brothers alive. Both of them were rescued, creating an unforgettable experience of joy and excitement for the rescue workers. During the 130 hours when the Sun brothers were trapped inside the collapsed building, they continued to have strong survival wills and encouragement from each other. They survived relying on mineral water and apples in their refrigerator and dripping water from the rescue operation. This story not only shocked the nation, but also inspired the rescue workers participated in the mission. However, from the $7^{\text {th }}$ day to the $10^{\text {th }}$ day, no more survivors were found. The death toll reached 73 persons. The rescue operation stopped on September 30 .

\section{THE RISK FACTORS OF BUILDING COLLAPSE RESCUE}


The most serious damage that an earthquake can create is building collapses. When a building collapses, it not only takes away lives of many residents, but also traps survivors with reinforced concrete. These survivors could die because the rescue workers could not get to them soon enough. Therefore, there is the so-called "golden 72 hours" in earthquake rescues. Simply put, it means that the people rescued within the first 72 hours after the earthquake have the highest survival rates. As we know, the building collapse rescue is very difficult. The rescue workers not only have to race against time, but also need to prevent secondary disasters created by aftershocks. The following are the risk factors involved in the rescue operation:

1. Building collapses: The rescue operation in collapsed building is a very difficult task that requires special skills. The hallways of the building are usually impassable due to the earthquake damages. The rescuers need to create their own pathways while applying supports to the damaged structure. If the building structure is severely damaged by the earthquake, it is very likely to continue collapsing and create more hazards to the rescuers and the persons trapped inside.

2. Building collapses due to improper demolitions: In the excavation process to rescue survivors, if the excavation is not done correctly, further building collapses can be resulted to threaten both the survivors and the rescue workers.

3. Falling objects: After the earthquake, the interior decoration and hanging objects could become loss and fall to injure rescuers.

4. Gas leaks: A building's natural gas is usually supplied by pipelines or barrels. The pipelines could break and gas leak might occur after an earthquake. Similarly, gas leak might occur to barrels, in which case the gas will accumulate inside the building because of the gas' higher than air density. If naked flame is presented, serious explosion can occur.

5. Fires: Fires could start due to gas leaks and create serious obstacles to the rescue operation. Especially the heavy smoke accompanying the blaze would critically diminish the survival chances of the people trapped inside the building.

6. Aftershocks: The aftershocks could trigger complete collapses of the damaged building. Therefore, the rescue operation needs to be temporarily suspended to protect the rescue workers when the aftershocks do occur.

7. Electric shocks: If the electricity to the building is not properly cut off, the rescuers can injure themselves by touching fallen electric lines.

8. Falls: To search for survivors, rescue workers sometimes need to climb the tilted buildings. They could lose balance and fall.

\section{THE RESCUE AND DEMOLITION PLAN OF COLLAPSED BUILDINGS}

All levels of government agencies need to participate in the search and rescue operations after the earthquake. Although there is not enough time to plan for the demolition of the building due to the emergency nature of the operation, we can not ignore the possibility of accidents to jeopardize the rescue workers.

\subsection{Rescuing people from the collapsed building}

The rescue workers of collapsed buildings should have professional rescue training and should be equipped with personal safety gear and proper rescue equipment. Before the rescue operation, they should understand the floor plans of the collapsed building, and plan the rescue routes in advance. Targeting the possible locations of survivors, the stability of the building needs to be evaluated by professional engineers to determine the possible direction of collapses and apply proper temporary supports before proceeding the rescue operation.

\subsection{Demolishing the collapsed building}

It is found that the common demolition equipment includes excavators, wrecking balls, cranes, hydraulic breakers, back-hoes, Bobcats, gas cutters, supply vehicles, and tip trucks. For ordinary building demolition, demolition coordinators rarely use one single demolition equipment for the job. Typically, a number of equipment has to be used at the same time according to the site conditions.

The building demolition program can be divided into two categories - the normal demolition and the emergency demolition. The major difference is that the emergency demolition has time constraints. Because the buildings damaged by earthquakes are usually in an unstable state, the emergency demolition and the emergency rescue usually proceed at the same time. It is therefore easy to neglect important tasks such as pre-demolition site inspections, demolition program developments, safety measures arrangements, and personnel training. As a result, it is more dangerous to perform emergency demolitions than normal demolition. The field commander needs to take this into account in advance [1].

\subsection{Preventing accidents}

From the study of risk factors of collapsed buildings, we found that in rescue operations the major risk factors were: building collapses, falling objects, gas leaks, fires, aftershocks, electric shocks, and falls. Their preventive measures are shown in Table 1. 


\subsection{Establishing an emergency resource look-up system}

This system should contain information on rescue organizations, rescue workers, emergency equipment, emergency supplies, hospital locations, lifeline facilities, street maps, and traffic networks. This information will be a valuable reference for developing a disaster mitigation plan before the disasters strike and an important basis for making decisions during the disasters $[2,3]$.

\section{CONCLUSION}

Due to the unpredictability of earthquakes using the current technologies, in order to reduce causalities caused by building collapses, it is necessary to collect relevant information before the earthquakes strike. This information includes the infrastructures, environments, and population distributions. Then, earthquake hazard analysis can be performed to develop disaster mitigation action plans and conduct emergency rescues in the disaster. For better and more effective search and rescue operations, specialized rescue personnel need to be trained in countries with advanced technologies. New life detectors should be purchased and listed in the databases of emergency equipment so that they can be properly used for quick responses when disaster happens. In order to accelerate building demolitions, heavy demolition equipment should be acquired and maintained. Finally, cooperative agreements should be signed with the civilian rescue forces and construction constructors to accomplish the necessary emergency demolitions in the disasters.

\section{REFERENCES}

[1] The Institute of Occupational Safety and Health, the Council of Labor Affairs, Executive Yuan of the Republic of China, The Investigation of Labor Safety and Compilation of Safety Manuals after the Ji-Ji Earthquake, Research Proposal, 1999.

[2] Tsai, B.-W., "The Development of a Disaster Response Support System," A Compilation of the 1999 Hazard Mitigation Research Project Reports, vol. 3, pp. 5.1-5.9, January 2000.

[3] Shih, B.-J., Chen, J.-H., and Wu, K.-C., "The Establishment and Applications of Geographical Information System for Disaster Mitigation and Emergency Rescues," Proceedings of the CrossStrait Conference on the Applications of GIS, $R S$, and GPS on Disaster Mitigation, Taipei, pp. 72-99, 1998.

Table 1 . The safety measures of collapsed buildings triggered by earthquakes

\begin{tabular}{|l|l|}
\hline Type of Hazard & Safety Measures \\
\hline Building collapses & $\begin{array}{l}\text { The damaged building should be examined by professional engineers and given the } \\
\text { necessary temporary supports. }\end{array}$ \\
\hline $\begin{array}{l}\text { Building collapses due to } \\
\text { improper demolitions }\end{array}$ & $\begin{array}{l}\text { The demolition procedure needs to be implemented by professional engineers. No } \\
\text { one should be allowed to enter the damaged building while the demolition is taking } \\
\text { place. }\end{array}$ \\
\hline Falling objects & $\begin{array}{l}\text { Rescue workers should be equipped with personal safety gear. Supervisors should be } \\
\text { designated to monitor the stability of the damaged building. }\end{array}$ \\
\hline Gas leaks & Ventilate the closed space first, and then turns off the gas supply. \\
\hline Fires & $\begin{array}{l}\text { Rescue workers should wear protective gear and use fire engines to extinguish the } \\
\text { fire. }\end{array}$ \\
\hline Aftershocks & $\begin{array}{l}\text { Apply temporary supports to the structure. When aftershocks occur, the rescue } \\
\text { workers should withdraw from the site immediately. }\end{array}$ \\
\hline Electric shocks & $\begin{array}{l}\text { Investigate the site conditions in advance. Cut off electric supply, and remove } \\
\text { electric wires. }\end{array}$ \\
\hline Falls & Use stable ladders and wear safety belts. \\
\hline
\end{tabular}

